\title{
Patrimônio cultural, turismo e gestão pública: exploração turísti- ca predatória e desvalorização patrimonial em Igarassu, Brasil
}

\author{
André Fontan Köhleri \\ Universidade de São Paulo (Brasil)
}

Resumo: O objeto de estudo do artigo é o conjunto arquitetônico e paisagístico de Igarassu, mais especificamente as inter-relações entre patrimônio cultural, turismo e gestão pública no sítio histórico. O trabalho de campo mostrou que o atual padrão de exploração turística é um instrumento de desvalorização e deterioração desse patrimônio, deixando reduzidos benefícios à cidade. Isso é resultado do controle externo do fluxo de turistas e visitantes, bem como da falta de controle e regulação públicos efetivos da prefeitura municipal. Considerando as características do mercado turístico, especificamente das agências e guias de turismo, e da gestão pública em Igarassu, avaliam-se como improváveis mudanças relevantes nas inter-relações supracitadas, pelo menos a curto e médio prazo.

Palavras-chave: Patrimônio cultural; Turismo cultural; Gestão pública de cultura e turismo; Agências de turismo receptivo; Guias de turismo; Impactos sócio-econômicos e culturais.

Title: Cultural heritage, tourism and public management: predatory tourism and heritage devaluation in Igarassu, Brazil.

\begin{abstract}
The subject of this article is the architectural and landscape complex of Igarassu, more specifically the interrelationships between cultural heritage, tourism and public management in the historic site. The field work showed that the current pattern of tourism is an instrument of devaluation and deterioration of this heritage, leaving reduced benefits to the city. This results from the external control of the flow of tourists and visitors, as well as the lack of effective public control and regulation by local government. Given the nature of the tourism market, specifically the agencies and tour guides, and public management in Igarassu, relevant changes in the interrelationships cited above are assessed as unlikely to happen, at least in the short and medium term.
\end{abstract}

Keywords: Cultural heritage; Cultural tourism; Cultural and touristic public management; Receptive tourism agencies; Tour guides; Socio-economic and cultural impacts.

\footnotetext{
i Professor Assistente Ref. MS-2 do Curso de Bacharelado em Lazer e Turismo da Escola de Artes, Ciências e Humanidades da Universidade de São Paulo (EACH/USP). Docente das disciplinas ACH1543 - Economia do lazer e turismo, ACH1534 - Impactos sócio-econômicos do lazer e turismo e ACH3598 - Políticas de cultura. E-mail: afontan@usp.br
} 


\section{Introdução.}

O objeto de estudo do artigo é o conjunto arquitetônico e paisagístico de Igarassu, mais especificamente as inter-relações existentes entre patrimônio cultural, gestão pública de cultura e turismo e exploração turística no sítio histórico da cidade.

O trabalho apresenta três objetivos principais, complementares entre si: a) avaliar o padrão de exploração turística do sítio histórico de Igarassu, buscando-se compreender como se organiza esse turismo e seus principais impactos sociais, econômicos e culturais; b) avaliar as relações entre turismo e patrimônio cultural, tanto o consumo efetivo quanto a utilização dessa atividade para se justificar iniciativas patrimoniais públicas; e c) avaliar a gestão pública de cultura e turismo, desde a formulação e implantação de grandes programas e projetos até o controle e regulação públicos das atividades no sítio histórico.

A metodologia de pesquisa compreende revisão de literatura analítica, pesquisa documental, entrevistas, observação participante e levantamento fotográfico. Foram feitas entrevistas abertas e semi-estruturadas, com a finalidade de capturar toda a riqueza de opiniões sobre as inter-relações entre patrimônio cultural, turismo e gestão pública no sítio histórico de Igarassu. Elas foram feitas com ocupantes das principais posições-chave, i.é, aquelas definidas pelas principais perspectivas de interesse material, simbólico e político, levadas a pensar os projetos em si e esse tipo de política pública. Ao todo, foram feitas mais de trinta entrevistas nas cidades do Recife, Igarassu e São Paulo.

As experiências de observação participante contemplaram a visita a Igarassu através de passeios de agências de turismo receptivo, ida a postos de informações turísticas localizados no Recife, contratação de guias embaçadores em Igarassu e observação de como os turistas independentes e organizados visitam o sítio histórico.

Desde o final dos anos 1960, diversos programas e projetos públicos tentaram transformar Igarassu em importante destino turístico, o que nunca de fato ocorreu. A cidade sempre participou da promoção turística do governo estadual, e a prefeitura municipal vem distribuindo panfletos e cartazes no sítio histórico desde os anos 1970 - isso também não tem surtido muito efeito sobre o número de visitantes.

O sítio histórico de Igarassu é um espaço urbano que não sofreu um processo de turistificação (tourismification): processo através do qual as atividades turísticas marcam, moldam e influenciam a cidade ou espaço urbano, tanto na forma quanto na função; ou seja, a ma- neira e grau pelos quais o turismo gradualmente altera as formas urbanas, redefinindo o composto de funções e atividades da cidade ou espaço urbano (Jansen-Verbeke, 1998; Russo, 2002).

Em suma, não se trata de uma cidade turístico-histórica (tourist historic city), como parte da literatura analítica já se refere às principais cidades patrimoniais européias intensamente exploradas pelo turismo (Bryon e Russo, 2003) - e para as quais já se encontra abundância de estudos de caso no campo da cultura e turismo, ao contrário de sítios e destinos turísticos pouco explorados.

\section{Patrimônio cultural, turismo e gestão pública: in- ter-relações, tendências e conflitos.}

Segundo a Organização Mundial do Turismo (OMT) e a United Nations Statistics Division (UNSTAT), o turismo consiste na atividade de quem viaja ou permanece em lugar que não seu ambiente normal por não mais do que um ano consecutivo, em razão, entre outras, de lazer ou trabalho (Cooper et al., 2001).

A partir de extensa revisão da literatura de conceitos empregados para definir o termo turismo, Tribe (1997: 641) oferece definição ampla, que captura a complexa e multifacetada natureza da atividade: "[Turismo é] o conjunto dos fenômenos e das relações que emergem da interação em regiões emissoras e receptivas, de turistas, empresas fornecedoras, órgãos de governo, comunidades e ambientes."

McKercher e Du Cros (2003) definem turismo cultural como o consumo turístico de atrações previamente classificadas como culturais. O conceito de patrimônio cultural da International Commission on Monuments and Sites (ICOMOS) é usado para definir a oferta de atrações culturais de uma cidade, região ou país:

Patrimônio cultural é um conceito amplo que inclui bens tangíveis, como ambientes naturais e culturais, incluindo paisagens, locais históricos, sítios e ambientes construídos, assim como bens intangíveis como coleções, práticas culturais passadas e atuais, conhecimento e experiências de vida. Exemplos de patrimônio tangível incluem museus, prédios históricos, sítios religiosos e talvez parques temáticos, se eles têm um foco patrimonial, enquanto o patrimônio intangível inclui coleções, performances e festivais. Elas não incluem, no entanto, atrações turísticas que não têm um foco cultural ou patrimonial claro e reconhecível (McKercher e Du Cros, 2003: 48).

O turismo cultural vem apresentando expressivo crescimento de mercado desde os anos 1980, transfor- 
mando-se de nicho especializado, composto por turistas com interesses estritamente culturais, em segmento do mercado de turismo de massa, no qual a visita e consumo de atrações culturais combinam-se a outros interesses e atividades. McKercher (2002) e McKercher e Du Cros $(2002,2003)$ subdividem os turistas culturais em cinco tipos, não apenas em virtude da importância das atrações culturais visitadas na escolha do destino turístico, mas também do nível de envolvimento do turista com o patrimônio visitado; o padrão de visitas e atrações culturais visitadas difere de grupo para grupo.

A literatura analítica apresenta diversos estudos de caso que demonstram a importância do turismo cultural para a economia de médias e grandes cidades européias, apesar dos relevantes impactos negativos gerados pela atividade em alguns casos: Veneza, Itália (Russo, 2002), York, Reino Unido (Snaith e Haley, 1999; Meethan, 1996) e Cambridge, Reino Unido (Maitland, 2006); Borg, Costa e Gotti (1996) sumarizam o resultado de pesquisa realizada pelo International Center of Studies on the Tourism Economy (CISET) da Universidade de Veneza, que demonstra a centralidade do turismo cultural para a economia de sete cidades patrimoniais européias dentro de um quadro geral de aumento da demanda desse segmento de mercado no meio urbano: Aix-en-Provence (França), Amsterdam (Países Baixos), Bruges (Bélgica), Florença e Veneza (Itália), Oxford (Reino Unido) e Salzburg (Áustria).

Muitas cidades especializaram-se no atendimento ao segmento de turismo cultural, tendo um sistema de atrações turísticas muito mais amplo e diversificado do que seus principais monumentos, festas tradicionais e artesanato local, e uma gestão pública de cultura e turismo que não se preocupa apenas com a preservação do patrimônio e fomento e promoção turística.

York, Reino Unido, foi apontada como o principal destino turístico britânico após Londres pela Touche Ross Management Consultants em 1994 (Snaith e Haley, 1999). Meethan (1996) sustenta que a narrativa espacial da cidade intramuros de York revela como seu principal valor os promissores e interligados ramos do turismo e comércio especializado de luxo, aos quais o patrimônio edificado serve como suporte de atividades econômicas e principal atração turística da cidade. Essa interligação entre patrimônio e turismo intensificou-se ao longo dos anos, resultando em pontos como a abertura de atrações turísticas pagas com foco patrimonial, criação de novos eventos "tradicionais" e reconstrução de espaços urbanos com estilos arquitetônicos passados e atavios patrimoniais. Tudo isso foi acompanhado por crescente regulação pública sobre o uso e ocupação do solo na cidade intramuros; em suma, a preservação pa- trimonial e intervenção pública seguem os interesses do turismo e comércio especializado de luxo na área.

Entretanto, na maioria das vezes a gestão pública do turismo resume-se à sua promoção e fomento, mesmo que planos e estratégias de desenvolvimento defendam um papel mais amplo e ativo ao poder público, e/ou que a capacidade de carga da cidade já tenha sido ultrapassada, ocasionando impactos sócio-econômicos e culturais negativos advindos do excesso de turistas e visitantes.

Borg, Costa e Gotti (1996) levantam três pontos concernentes às políticas públicas de turismo das sete cidades patrimoniais européias pesquisadas: (a) existência de uma estratégia de administração do turismo formulada e implantada; (b) existência de parcerias entre o poder público e iniciativa privada; e (c) histórico de medidas efetivas já tomadas. Para o último ponto, os autores chegam à conclusão de que, com exceção de Salzburg, os resultados são irrelevantes para toda a mostra de cidades pesquisadas.

As políticas públicas de turismo resumem-se, na prática, ao fomento e promoção turísticos, sem a preocupação de se regular o desenvolvimento do turismo na localidade. No discurso, a sustentabilidade é mister; na prática, quanto mais turistas, excursionistas e, conseqüentemente, dinheiro melhor, mesmo que a exploração turística revele-se insustentável a longo prazo (Borg, Costa e Gotti, 1996).

As inter-relações entre patrimônio cultural, gestão pública e turismo no Brasil apresentam algumas particularidades; cabe fazer duas observações importantes sobre a realidade brasileira antes de entrar no estudo de caso desse artigo.

A falta de recursos, tanto na recuperação de conjuntos e monumentos degradados quanto na preservação de bens tombados, o desuso do patrimônio protegido e a pouca atratividade desse tipo de bem cultural fizeram com que, em meados dos anos 1990, segundo dados do próprio Instituto do Patrimônio Histórico e Artístico Nacional (IPHAN), cerca de 50\% dos imóveis históricos sob tutela federal se encontrassem degradados e $25 \%$ necessitassem de obras de recuperação. Esta mesma pesquisa indicou, ainda, que aproximadamente dois terços desses imóveis encontravam-se abandonados ou subutilizados (Taddei, 1998). Ainda de acordo com essa fonte, seria necessário, a época, o equivalente a US\$ 1 bilhão para a recuperação integral do acervo então tombado, bem como o dispêndio de US $\$ 50$ milhões anuais para sua conservação.

Não há um histórico de políticas públicas estruturadas voltadas à exploração turística do patrimônio cultural brasileiro. A primeira proposta relevante nesse sentido, o Programa de Reconstrução das Cidades 
Históricas do Nordeste, com sua utilização para fins turísticos (PCH), foi criado em 1973 e extinto em 1985. O programa conseguiu direcionar recursos relevantes para serviços de conservação patrimonial, tendo relativo sucesso nessa área; entretanto, ele nunca conseguiu promover o turismo nas cidades patrimoniais envolvidas, como será mostrado a seguir para Igarassu.

A segunda proposta relevante é o Programa MONUMENTA, criado em 1999 e ainda em vigor, que conta com recursos do Banco Interamericano de Desenvolvimento (BID). Seus resultados na área de conservação patrimonial variam de cidade para cidade; ainda não há estudos conclusivos sobre o objetivo de se desenvolver o turismo cultural nos espaços recuperados para esse fim, mas os distritos turístico-culturais criados no Recife e Salvador - Bairro do Recife e Pelourinho, respectivamente - não conseguiram se manter como espaços turísticos no longo prazo.

\section{Cidade patrimonial de Igarassu: formação, desen- volvimento e potencial turístico.}

A Vila de Igarassu foi fundada em 1535, tendo sido a primeira da Capitania de Pernambuco e um dos inícios da colonização efetiva do território brasileiro. As cidades de Olinda e João Pessoa foram fundadas por incursões de colonos e soldados portugueses partidas de Igarassu, daí o título de cidade mãe de Olinda e João Pessoa e avó do Recife (Universidade Federal de Pernambuco, 1974; Freyre, 1968a, 1968b).

Atualmente, Igarassu faz parte da Região Metropolitana do Recife (RMR), tem uma área de trezentos e seis quilômetros quadrados, e conta com uma população estimada de 100.191 habitantes em 2009 (Fundação Instituto Brasileiro de Geografia e Estatística, 2003). Sua zona rural ainda é dominada pelas culturas da cana-deaçúcar (interior) e coco-da-baía (litoral). Em 2002, 46\% do Produto Interno Bruto (PIB) municipal foi gerada pelo setor secundário, percentagem superior à média nacional e estadual (Fundação Instituto Brasileiro de Geografia e Estatística, 2005).

Igarassu ainda funciona em parte como cidade-dormitório do Recife. A cidade apresenta graves problemas sociais, dos quais se destacam: a) alto índice de desemprego; b) aumento da violência, prostituição e tráfico de entorpecentes nos últimos anos; e c) infra-estrutura urbana precária, principalmente na sua periferia urbana.

Igarassu apresenta grande potencial turístico, devido à sua localização, importância histórica e presença de inúmeros elementos naturais e culturais de interesse turístico. A cidade localiza-se a apenas trinta e dois quilômetros do Recife e a menos de cem quilômetros de Porto de Galinhas e João Pessoa, todos importantes destinos turísticos nacionais conectados a Igarassu por estradas em bom ou razoável estado de conservação.

Igarassu ainda conta com muitas áreas preservadas que retratam a paisagem natural encontrada pelos colonizadores portugueses na primeira metade do século XVI. O patrimônio cultural imaterial de Igarassu testemunha o sincretismo afro-indígena e a monocultura da cana-de-açúcar da Zona da Mata Norte pernambucana: maracatu, caboclinhos, ciranda, pastoril, marujada e bumba-meu-boi, entre outras. O principal grupo artístico da cidade é o Maracatu Estrela Brilhante, fundado em 1824 e um dos mais antigos do país. Assim como o patrimônio cultural imaterial, a produção artesanal também não é contemplada pelo Inventário do Potencial Turístico de Igarassu (Igarassu, 2005); ela não se distingue do artesanato encontrado em outros destinos turísticos da Região Nordeste do Brasil.

O conjunto arquitetônico e paisagístico de Igarassu foi inscrito no livro arqueológico, etnográfico e paisagístico do IPHAN através do processo 359-T-45 em 10/10/1972 (Instituto do Patrimônio Histórico e Artístico Nacional, 1994). Ele ocupa uma área de 396.202 metros quadrados, da qual o sítio histórico ocupa uma pequena parte. A Foto 1 ilustra o reduzido tamanho do sítio histórico, conseguindo capturar praticamente toda sua extensão:

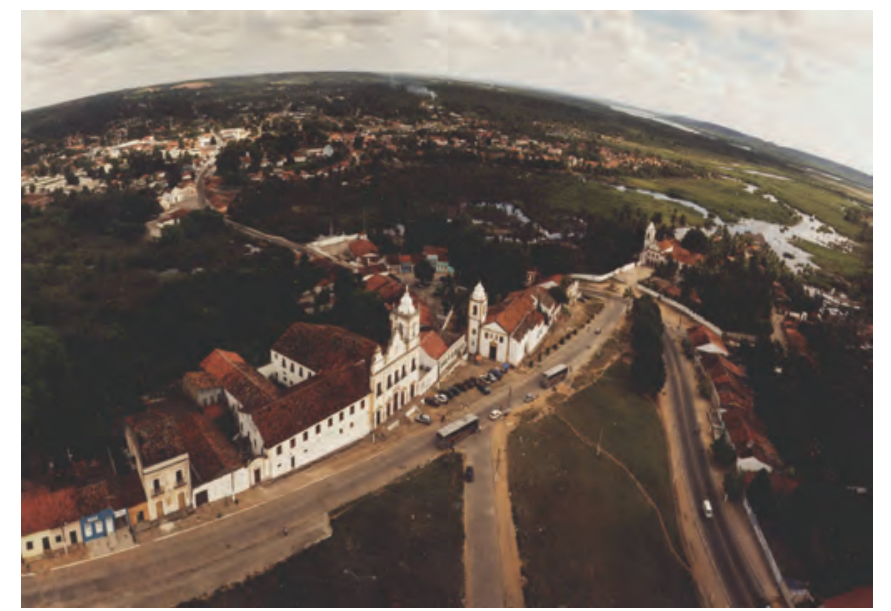

Foto 1: Vista aérea do sítio histórico de Igarassu. Fonte: Igarassu (2005).

O conjunto arquitetônico e paisagístico de Igarassu é um dos principais testemunhos materiais do Brasil Colônia (1500-1822), através tanto de bens culturais edificados de pedra e cal, herança da colonização portuguesa, quanto de remanescentes de vegetação nativa ou introduzida nos primeiros anos da colonização.

A presença de mangues, alagados e terrenos com alta declividade fez com que o entorno do sítio histórico de- 
monstrasse certa capacidade de resistência às pressões de ocupação geradas pelo adensamento populacional da RMR e implantação de grandes indústrias em Igarassu a partir dos anos 1960 (Universidade Federal de Pernambuco, 1974). Contudo, esse entorno sofre atualmente um processo de ocupação irregular, com a formação de favelas e pequenos núcleos habitacionais.

As edificações religiosas são os principais pontos de referência do sítio histórico, e possuem arquitetura monumental, com exceção da Capela de São Sebastião e Igreja de Nossa Senhora do Livramento (Universidade Federal de Pernambuco, 1974). Todas são tombadas pelo IPHAN, destacando-se:

a) Igreja dos Santos Cosme e Damião: construída em 1535, é a mais antiga igreja remanescente do Brasil (Teixeira, 1998). Situa-se na parte alta do sítio histórico, ao lado do Museu Histórico de Igarassu (MHI) e defronte da Igreja e Convento do Sagrado Coração de Jesus;

b) Igreja e Convento do Sagrado Coração de Jesus: construção de meados do século XVIII - trata-se do primeiro convento dessa ordem religiosa no Brasil (Igarassu, 2005);

c) Igreja e Convento de Santo Antonio: fundado em 1588. A primeira edificação, feita em taipa, foi substituída por construção de pedra e cal entre 1592 e 1594 (Fundação do Patrimônio Histórico e Artístico de Pernambuco, 1985). A pinacoteca instalada na sala dos noviços é considerada a mais importante da fase colonial brasileira, tendo destaque internacional (Tirapeli, 1999; Teixeira, 1998).

Os três monumentos listados acima estão em bom estado de conservação, sendo abertos à visitação. Outros prédios de destaque arquitetônico são a Casa de Câmara e Cadeia e o Sobrado do Imperador.

O casario histórico é formado por exemplares dos séculos XVII, XVIII, XIX e início do XX, e se encontra em bom estado de conservação; o tombamento do IPHAN contempla apenas a fachada e coberta das edificações. $\mathrm{O}$ acervo tombado apresenta integridade e harmonia arquitetônica difíceis de se encontrar em outras cidades patrimoniais brasileiras.

As casas são de arquitetura simples, térreas e com poucos elementos decorativos na fachada, com exceção de apenas três exemplares. O casario mantém as três características das cidades brasileiras durante o período colonial: (a) arquitetura colonial, que dá a aparência de cidade portuguesa; (b) lote urbano colonial derivado do lote medieval-renascentista português, com pequenas adaptações; e (3) construções sobre os limites do lote urbano, sem recuos frontais ou laterais (Reis Filho, 2006).

\section{Histórico das políticas públicas de cultura e turis- mo em Igarassu.}

O turismo nunca foi uma atividade econômica importante para Igarassu, pois a cidade sempre foi uma breve parada de quinze a vinte minutos dentro de passeios de agências de turismo receptivo, como será visto adiante. Contudo, o turismo foi e ainda é a principal justificativa para a execução de serviços de conservação patrimonial, e o potencial turístico da cidade, mesmo nunca efetivado, fez com que ela tenha sido alvo de ambiciosos programas e projetos federais, estaduais e municipais de turismo cultural.

No início dos anos 1970, o conjunto arquitetônico e paisagístico de Igarassu enfrentava sérios problemas de conservação. Havia riscos de desmoronamento de prédios importantes - por exemplo, Casa de Câmara e Cadeia e Igreja e Convento de Santo Antonio -, e o casario histórico e monumentos padeciam com pichações, mutilações e inserções de grades e placas comerciais sem o mínimo controle urbano (Universidade Federal de Pernambuco, 1974; Brasil, 1976; Fundação do Patrimônio Histórico e Artístico de Pernambuco, 1985).

As primeiras ações turísticas em Igarassu datam do final dos anos 1960, com a criação da Empresa de Turismo de Pernambuco (EMPETUR). Eram ações pontuais, como o apoio e divulgação das festas tradicionais da cidade; a falta de documentação impede sua avaliação sobraram apenas pequenas notas e notícias de jornal.

Nos anos 1970 e 1980, a EMPETUR formulou diversos projetos turísticos para Igarassu. Eles têm características comuns, ao propor a exploração turística isolada de Igarassu, sem considerar outros destinos do litoral norte - rota ou região turística -, e avaliar a cidade como ótima opção de passeio de um dia, mas raramente como capaz de sediar meios de hospedagem.

Todos os projetos privilegiam o acervo arquitetônico e artístico do sítio histórico de Igarassu, desconsiderando as outras atrações culturais e naturais do restante da cidade. Pela leitura da documentação, é como se a maior parte dos turistas tivesse um interesse muito específico em história, cultura e patrimônio, mesmo Pernambuco tendo sua imagem associada ao composto sol, mar e praia.

O nível de implantação dos projetos é muito baixo ou mesmo nulo para todos eles, sem exceção. Funcionários que trabalham na Prefeitura Municipal de Igarassu (PMIg) desde os anos 1970 revelaram em entrevistas que nem ao menos os nomes dos projetos são familiares.

Por exemplo, o projeto mais estruturado de todos Rota da Memória Histórica Pernambucana - Igarassu - previa nove ações conjuntas no sítio histórico: (a) es- 
tudo de viabilidade para implantação de restaurantes turísticos; (b) estudo de viabilidade para implantação de uma pousada no sítio histórico; (c) criação de roteiros de visitas aos monumentos selecionados; (d) implantação de posto de informações turísticas; (e) melhoria dos serviços de recepção do MHI e da pinacoteca do Convento de Santo Antonio; (f) implantação do centro turístico municipal no prédio da antiga Casa de Câmara e Cadeia; (g) edição de material informativo; (h) treinamento e/ou aperfeiçoamento de pessoal; e (i) criação de um centro de arte (embrião do Programa Cidade das Artes) (Empresa de Turismo de Pernambuco, 198-?). O trabalho de campo e pesquisa documental revelaram que nenhuma das nove ações foi implantada.

No final dos anos 1980, o litoral norte entrou em franco processo de decadência turística, que se estende aos dias atuais. O fluxo de turistas, visitantes e veranistas caiu; cessaram-se os investimentos em novos meios de hospedagem, e houve o encerramento de hotéis e marinas. A pauta das agências de turismo receptivo voltou-se ao litoral sul, principalmente Porto de Galinhas. Acompanhando tudo isso, os investimentos públicos de turismo concentraram-se no Recife, Olinda e litoral sul a partir dos anos 1990, caso do Programa de Desenvolvimento Turístico do Nordeste (PRODETUR/NE) (Empresa de Turismo de Pernambuco, 1997).

Enquanto os projetos e ações de desenvolvimento turístico sempre apresentaram resultados pífios ou nulos, os programas e projetos de conservação patrimonial conseguiram transformar o sítio histórico de Igarassu em um dos mais bem preservados do Brasil nos últimos trinta e cinco anos. Talvez nenhuma outra cidade patrimonial brasileira tenha sido tão privilegiada em dotação de verbas e implantação de projetos, em relação ao tamanho do seu acervo artístico e arquitetônico. Com raras exceções, o turismo sempre ocupou um papel central nos objetivos e justificativas desses programas e projetos; cabe descrever e analisar os dois principais.

Desvinculado da orientação museológica do IPHAN, o PCH tinha como principal objetivo gerar desenvolvimento sócio-econômico em localidades pobres da Região Nordeste, que, em geral, tinham grande parte do seu patrimônio arquitetônico preservado decorrente da estagnação econômica pela qual tinham passado. Ou seja, ao invés de recuperar bens levando-se em conta exclusivamente seu valor histórico e artístico, o programa considerava o potencial turístico de conjuntos arquitetônicos e monumentos, preocupando-se com seu uso como instrumento de geração de emprego e renda (Miceli, 1984).

$\mathrm{O} \mathrm{PCH}$ contemplou pelo menos três projetos em Igarassu, dos quais foi possível recuperar a documentação de apenas um: a intervenção na Praça Marechal Deodoro (Brasil, 1976). Apesar de inovador à época, por contratar os residentes locais como mão-de-obra não qualificada, contemplar ações de educação patrimonial, e se preocupar com a utilização dos prédios restaurados, esse projeto não efetivou nenhuma ação turística, nem envolveu órgãos públicos de turismo. Mesmo contando com uma equipe multidisciplinar, a passagem "com sua utilização para fins turísticos" ficou apenas no subtítulo do programa, como relataram a assistente estadual e historiador entrevistados no trabalho de campo que participaram e acompanharam o supracitado projeto.

O Projeto de Restauração e Instalação do Museu do Convento de Santo Antonio fez parte do Programa Especial para a Região Metropolitana do Recife (Fundação do Patrimônio Histórico e Artístico de Pernambuco, 1985). O projeto tinha três objetivos: a) restaurar o conjunto arquitetônico e seu acervo de bens móveis; b) transformar parte do monumento histórico em museu, com a separação das funções museológicas, religiosas e escolares, convertendo-o em centro cultural de referência para todo o Estado de Pernambuco; e, conseqüentemente, c) elevar a Igreja e Convento de Santo Antonio à condição de atração turística "obrigatória” de Pernambuco. Para isso, previa-se a delimitação das áreas do museu e uso privativo das freiras, assim como a construção de um anexo para suportar as funções escolares. O projeto previa também dotar o monumento de estrutura turística, com posto de informações e bilheteria, ponto de venda de artesanato, lanchonete e bateria de sanitários.

Tratou-se do maior projeto cultural da história do governo estadual, iniciado em 1985 e terminado apenas em 2001-2002, ainda não tendo sido superado em volume de recursos ou repercussão nacional e internacional. A Igreja e Convento de Santo Antonio foi o primeiro monumento fora da Europa a receber recursos da União Européia para conservação patrimonial, através do Programa Raphäel (Teixeira, 1998).

Entretanto, a estrutura turística nunca saiu do papel, com exceção de parte da lanchonete. O plano de gestão do monumento também não foi implantado (Fundação do Patrimônio Histórico e Artístico de Pernambuco, 1993), gerando uma indefinição de funções e responsabilidades para com o monumento que persiste até hoje. Funcionários da Fundação do Patrimônio Histórico e Artístico de Pernambuco (FUNDARPE) afirmaram em entrevistas que a estrutura turística não representava 5\% do custo total do projeto; um arqueólogo da FUNDARPE sintetiza a falta de definição que perdura até hoje: "Ficou-se sem uma decisão: atende-se em parte e mal as crianças e os visitantes, Porque ainda não houve, e esse é um dos grandes problemas nossos, uma decisão. 
Tome-se uma decisão errada, mas que se decida alguma coisa." (Entrevista no Recife, 06/07/2005).

Em suma, as políticas públicas de cultura e turismo deixaram como legado um dos sítios históricos mais bem preservados do país, contudo pouco visitado por turistas e visitantes. $\mathrm{O}$ turismo transformou-se em justificativa e objetivo de grandes projetos de conservação patrimonial, mas nunca foi efetivado como atividade econômica importante para Igarassu.

Gestão pública de cultura e turismo: caracterização e resultados da ênfase em grandes projetos "transformadores."

As funções de cultura e turismo são de responsabilidade da Secretaria de Turismo, Cultura e Esportes (STCE). Apesar de o conjunto arquitetônico e paisagístico de Igarassu ser tombado pelo IPHAN desde 1972, e de a PMIg acreditar no potencial turístico do município, a STCE ocupa uma posição periférica dentro da estrutura de governo. Isso se traduz tanto na falta de verbas quanto na dificuldade de interlocução com as outras pastas municipais, como expõe o ex-secretário municipal (2001-2004):

A questão principal é que os recursos para a STCE são muito poucos; Saúde, Educação e Assistência Social determinam o que deve ser gasto dentro do orçamento. Como Igarassu é uma cidade pobre, a área social sempre tem o maior orçamento, e consegue, durante o ano, ter um desempenho melhor, também porque tem a grita do povo e da Câmara Municipal para que elas sejam atendidas. (Entrevista na Cidade do Paulista, 21/07/2005).

A equipe da STCE é formada por funcionários de carreira - de baixa qualificação - e em cargos de confiança, cuja escolha segue critérios preponderantemente políticos, o que faz com que a maioria não tenha qualquer experiência prévia nas áreas de cultura e turismo. O ex-secretario municipal (2001-2004) admite a falta de preparo do corpo funcional:

A [minha] ida a essa secretaria foi por determinação política e administrativa do prefeito, como em todo o município. [...] A montagem da equipe técnica tem algumas nuances, sendo a determinação política a mais forte. Em virtude da montagem da base de sustentação do governo, a equipe técnica de fato é muito reduzida na administração pública municipal. (Entrevista na Cidade do Paulista, 21/07/2005).

Outra característica da STCE é a natureza de cima para baixo (top down) da gestão pública. As idéias e projetos são formulados e eventualmente implantados pelo secretário municipal, quando muito discutidos com um ou outro funcionário mais graduado, e poucas vezes formalizados em documentos. O diretor do MHI (20052008) comenta sobre um ex-secretário municipal (19972000): "[Nome do indivíduo] é uma incógnita para mim. Ele passou quatro anos como secretário municipal, e nunca conversou comigo." (Entrevista em Igarassu, 20/07/2005).

A STCE sofre da descontinuidade administrativa, mesmo quando o atual e ex-prefeito são do mesmo grupo político. Isso é visível na falta de memória administrativa da pasta municipal. Por exemplo, o Plano de Gestão do Turismo para o Município de Igarassu, publicado em 2002, e que se propunha a estruturar o desenvolvimento turístico no longo prazo (E.L.T. Consultoria, Igarassu e Serviço de Apoio às Micro e Pequenas Empresas de Pernambuco, 2002), é desconhecido por todos os entrevistados da gestão posterior (2005-2008). Sobre a transição de governo, o diretor de promoção e eventos da STCE (2005-2008) comenta:

Não houve nenhum encontro, nenhuma transição entre a equipe de turismo passada e atual. Nunca houve uma reunião ou encontro para sabermos o que a gestão passada fez ou deixou de fazer. [...] Eu não tive acesso a nenhum projeto da gestão passada. A atual equipe, que veio toda do Recife, está começando do zero. (Entrevista no Recife, 05/07/2005).

A gestão de cultura e turismo também não é permeável à participação da população local, sejam os residentes locais ou empresários envolvidos com o turismo - efetiva ou potencialmente. O diretor de promoções e eventos da STCE (2005-2008) resume o que significa o turismo para os residentes locais, noção essa confirmada no trabalho de campo: "O problema, na verdade, é que... [silêncio] O turismo ainda é tido, para a população de Igarassu, como um bicho-papão." (Entrevista em Igarassu, 05/07/2005).

A partir de 1997, a STCE concentrou-se na proposição de grandes projetos transformadores, ao mesmo tempo em que carências e problemas básicos do sítio histórico não foram alvo de ações públicas efetivas. Dos cinco grandes projetos propostos, foi possível encontrar documentação referente apenas ao intitulado "Refazendo os caminhos de Duarte Coelho," um dos dois implantados. Ele ilustra bem a convivência de grandes projetos transformadores com a ausência de controle e regulação públicos em Igarassu.

O projeto objetivava transformar o Sítio dos Marcos - local onde Duarte Coelho Pereira desembarcou em 1535 - em importante pólo de turismo histórico-cultural 
e natural. Para tal, previa o agenciamento paisagístico do entorno, construção de praça arborizada, área para eventos, estacionamento, bancos, gruta e quiosque para informações turísticas e comercialização de artesanato e restauro da réplica do marco de pedra. Numa segunda fase, previa-se a construção de um ancoradouro na Praia dos Marcos para proporcionar passeios até a Ilhota Coroa do Avião para os turistas e visitantes ${ }^{1}$.

O projeto aplicou $\mathrm{R} \$ 514.089,42$ no Sítio dos Marcos e em sinalização turística, implantando toda a infraestrutura, mobiliário urbano e edificações previstas na primeira etapa, além de melhorar a estrada de barro de acesso. Entretanto, o local nunca recebeu muitos turistas e visitantes, inclusive pelo fato de o projeto não ter sido concluído, e também pela falta de manutenção e mínimo controle urbano. $\mathrm{O}$ ex-secretario municipal da STCE (2001-2004) justifica o insucesso turístico do Sítio dos Marcos, já que o pretendido novo espaço turístico converteu-se em mais um espaço abandonado da cidade, apontando que o projeto está incompleto:

[O Sítio dos Marcos] Não é um ponto de consumo turístico, porque faltaram etapas importantes para se consolidar o projeto. Para um ônibus de turismo, a estrada tem algumas curvas muito acentuadas, e houve alguns avanços dos donos de sítios que ficam nos limites da estrada, que praticamente impossibilitam a entrada dos ônibus de turismo. [...] Não é que o projeto parou, mas ele não teve como ter continuidade nas outras etapas por falta de recursos. (Entrevista na Cidade do Paulista, 21/07/2005).

A ênfase em grandes projetos turísticos é resumida na seguinte passagem da entrevista com o diretor de promoção e eventos da STCE (2005-2008), ao responder à seguinte pergunta: "Você vê alguma alternativa para, em curto prazo e com poucos recursos, aumentar o gasto médio dos turistas em Igarassu?":

Um paliativo seria a criação de uma feira de artesanato, por exemplo. [...] Eu acho que uma feirinha de artesanato... [Silêncio] Seria um paliativo, mas não podemos pensar em paliativos, temos que procurar resolver os problemas. [...] Eu acho que esse gasto médio pode aumentar, mas a partir do momento em que a gente implantar os projetos. É necessário esquecer os paliativos, e executar os projetos. (Entrevista no Recife, 05/07/2005).

Ao mesmo tempo em que a cidade e sítio histórico de Igarassu são objetos constantes de grandes projetos turísticos e serviços de conservação patrimonial, diversos problemas e carências seguem sem ações efetivas da PMIg.

A cidade de Igarassu praticamente não conta com nenhuma sinalização turística desde a retirada das placas em 2001-2002. A quase ausência de sinalização turística e escassez de sinalização rodoviária refletemse na dificuldade de se chegar ao sítio histórico, caso o turista ou visitante viaje de modo independente. Por exemplo, do Recife a Igarassu há apenas uma placa de trânsito indicando a entrada ao sítio histórico, localizada a poucos metros do acesso. Ela é relativamente pequena e acanhada para as dimensões da BR-101; a Foto 2 mostra-a:

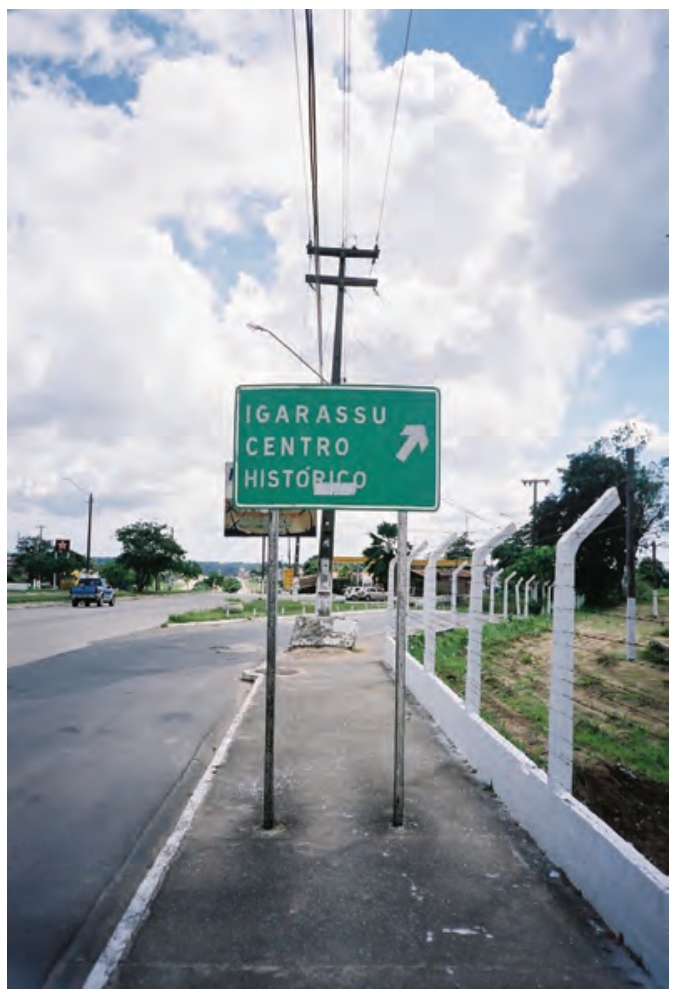

Foto 2: Placa de trânsito na BR-101 - Igarassu Centro Histórico. Fonte: Autor. A foto é de julho de 2005.

O trabalho de campo simulou a ida de um turista ou visitante de João Pessoa para Igarassu. Seguindose apenas as placas turísticas e de trânsito para o sítio histórico, ele chegará apenas em uma das duas cidades: Itapissuma ou Recife.

Igarassu não conta com posto de informações turísticas, e o material promocional (folhetos e cartazes) está constantemente em falta no MHI e principais monumentos históricos, mesmo eles sendo localizados a menos de quinhentos metros da sede da STCE; o diretor de promoção e eventos (2005-2008) reconhece a falha: "Serei bem sincero: o material não está em falta, o problema é que ele não está sendo bem distribuído. Nós precisamos criar uma forma de melhorar a nossa comunicação com 
os prédios históricos que funcionam e estão sob a nossa responsabilidade." (Entrevista no Recife, 05/07/2005).

Nenhum panfleto impresso nos últimos dez anos contou com mapa de localização da cidade, sítio histórico e/ ou atrações turísticas, nem com instruções sobre como se chegar em Igarassu e visitar seus principais atrativos. Bares, restaurantes, meios de hospedagem e lojas de artesanato não chegam a ser citados, assim como o serviço de guias mirins mantido pela PMIg.

O panfleto "Dive into the history," em inglês, retrata muito bem a falta de qualidade desse material promocional. $\mathrm{O}$ texto está escrito em inglês, porém as legendas das fotos estão todas em português. O texto, escrito em inglês precário, apresenta desafios para a compreensão do turista ou visitante estrangeiro, além do caráter fragmentado das informações turísticas:

It's main monuments are: the Cosme and Damião Saints' Church, founded in 1535 and considered the oldest still up, in Brazil, Santo Antônio Convent founded in Brasil, where the Pinacoteca Art Museum is installed.

In the museum, an important collection of the Brazil colonial.

As a seaside city, the small island Coroa do Avião is one of the most important natural tourist attraction. With $20.000 \mathrm{~m}$ in extension.

The maracatu (in Pernambuco, a group of street dancing,merrymakers at Carnival time)and baque-virado maracatu; a sea food based gastronomy (Igarassu, 199-?).

A infra-estrutura do sítio histórico de Igarassu é muito deficiente, dificultando sua exploração turística. Apesar de os monumentos e casario histórico estarem bem conservados, o calçamento cabeça-de-negro, remanescente do Brasil Colônia, encontra-se em péssimo estado de conservação, estando quase "extinto" em alguns trechos. Há muitos buracos e tampas de bueiro abertas, bem como falta de sinais e faixas de pedestre para se atravessar a avenida que corta o sítio histórico, dividindo a parte alta da Igreja e Convento de Santo Antonio. Não há sanitários públicos; há apenas dois telefones públicos, mas ambos ficam em locais pouco freqüentados pelos turistas e visitantes. Outro ponto que chama a atenção é a falta de policiamento na parte alta do sítio histórico - nas diversas visitas feitas durante o trabalho de campo, nunca foi avistado um policial ou guarda municipal nessa área.
A cidade de Igarassu não conta com uma superestrutura turística adequada, em virtude, inclusive, da decadência do litoral norte como destino turístico. Há apenas dois bares, uma loja de quinquilharias e um ponto de venda de artesanato em todo o sítio histórico; entretanto, nenhum deles localiza-se no Pátio dos Santos Cosme e Damião, onde se concentram os turistas e visitantes.

Cabe destacar que a Cidade de Igarassu não conta com muitos espaços e equipamentos culturais dentro ou fora do sítio histórico, como, por exemplo, museus, salas de exposição e auditórios. Não há políticas culturais efetivas que permitam aos residentes locais conhecerem e compreenderem melhor o sítio histórico, nem que lhes permitam freqüentar o sítio histórico dentro de propostas de lazer, entretenimento e educação; por exemplo, o sítio histórico não recebe ensaios e apresentações das manifestações tradicionais de Igarassu, que formam seu rico patrimônio cultural imaterial.

\section{Sítio histórico de Igarassu: padrão de explo- ração turística e seus principais impactos sociais, econômicos e culturais.}

A quase totalidade dos turistas e visitantes conhece Igarassu através de passeios de agências do Recife e João Pessoa. Segundo o diretor da Associação dos Agentes de Turismo de Igarassu, os passeios Recife-Itamaracá e João Pessoa-Recife respondem por 90\% do fluxo de turistas e visitantes no sítio histórico; optou-se por analisar aqui o passeio Recife-Itamaracá, pois ele responde pela maior parte do supracitado fluxo.

O passeio Recife-Itamaracá tem como principal atrativo o composto sol, mar e praia; após breve passagem pelo sítio histórico de Igarassu, os turistas permanecem por mais de seis horas nas praias da Ilha de Itamaracá. O passeio João Pessoa-Recife tem como principal atrativo o sítio histórico de Olinda e alguns monumentos no Recife; contudo, grande parte do tempo dos turistas é gasto nas lojas de artesanato, pois os guias de turismo conseguem ganhar uma comissão de até $20 \%$ do valor total gasto nessas lojas.

Como colocado anteriormente, o litoral norte encontra-se em decadência desde o final dos anos 1980; ambos os passeios são relativamente pouco vendidos dentro da pauta das agências de turismo receptivo. São produtos voltados para o turismo de massa; as agências delegam a seleção de o que ver no passeio para os guias de turismo, cuja preocupação fundamental é ganhar comissão sobre os gastos dos turistas. Quase não há diferenciação entre os passeios ofertados pelas diferentes agências, como confirma a funcionária de uma delas: "As agências 
de receptivo são iguais, têm o mesmo produto, visam o mesmo turista. O diferencial é preço e fazer contatos com o recepcionista de hotel. Os roteiros são exatamente o mesmo." (Entrevista no Recife, 01/06/2004).

Os turistas e visitantes concentram-se no tempo e espaço; os ônibus e vans de turismo chegam ao sítio histórico entre 09:00 e 13:00 hs, às terças e sextas-feiras. Apenas o Pátio dos Santos Cosme e Damião é visitado, e nele os turistas e visitantes entram apenas na Igreja dos Santos Cosme e Damião, gerando grandes concentrações pontuais de pessoas nesse monumento.

Os guias de turismo falam pouco sobre Igarassu durante o passeio; a comunicação centra-se na descrição e venda de outros passeios da agência, além de uma narrativa pobre e fragmentada sobre Itamaracá. Igarassu é retratada como uma breve parada, como mostra a seguinte narrativa de um guia turístico: "Vamos ficar apenas quinze minutos, pois temos que chegar a Itamaracá. A Igreja de Cosme e Damião é a primeira, não vamos visitar a outra por causa de tempo, temos que chegar em Itamaracá antes das 11:00 hs. (Observação participante em Igarassu, julho de 2005).

Há uma alça de estacionamento a cinqüenta metros do Pátio dos Santos Cosme e Damião; entretanto, os ônibus e vans estacionam ao lado ou em cima do pátio, deteriorando o calçamento cabeça-de-negro. Além disso, o veículo transforma-se numa barreira entre o turista e o restante do conjunto arquitetônico e paisagístico de Igarassu. Os guias de turismo não citam o MHI, e ignoram a Igreja e Convento do Sagrado Coração de Jesus. A Igreja e Convento de Santo Antonio - vista apenas pela janela - é apontada como estando fechada para restauro, o qual terminou em 2001-2002.

A seleção de o que ver e visitar - uma das funções básicas do guia de turismo - é acentuada em Igarassu, pois as agências competem principalmente através do preço dos passeios, em um quadro similar ao verificado em Hong Kong por Ap e Wong (2001). A pressão das operadoras de turismo pela diminuição das tarifas provocou o sucateamento das agências de turismo receptivo em todo o Brasil, com a conseqüente perda de qualidade dos passeios oferecidos (Gazeta Mercantil, 2000).

Logo, não é de se estranhar que os próprios proprietários, vendedores e atendentes tenham dificuldades para descrever o conteúdo dos passeios vendidos pela sua agência; ao ser questionado sobre o passeio RecifeItamaracá, um vendedor da segunda maior agência de Pernambuco assim respondeu, sem esconder sua impaciência: "Depende de cada guia. Você pergunte para ele, é ele que leva vocês durante o passeio. [...] Se pára ou não em Igarassu, eu não sei." (Observação participante no Recife, junho de 2005).
O guia de turismo molda toda a experiência do turista e visitante no sítio histórico e passeio como um todo - locais e atrações visitadas, tempo de visita, (falta de) contato com os habitantes locais, etc -, sendo favorecido pela ausência quase total de controle e regulação públicos.

A busca por ganhos de comissão sobre os gastos dos turistas é um dos principais determinantes, quando não o principal, da estruturação do passeio pelo guia de turismo (Ap e Wong, 2001; Nettekoven, 1979; Black, 1996). O trabalho de campo constatou que os guias de turismo ganham comissão de até $20 \%$ sobre esses gastos nos bares e restaurantes de Itamaracá, apesar de essa prática ser proibida por lei no Brasil. O sítio histórico de Igarassu não oferece essa oportunidade ao guia de turismo, pois há poucos negócios aptos a atender os turistas. Logo, quanto menos tempo em Igarassu, mais em Itamaracá - e, ceteris paribus, mais comissão para o guia de turismo.

A concentração dos turistas e visitantes no tempo e espaço faz com que a Igreja dos Santos Cosme e Damião sofra congestionamentos às terças e sextas-feiras, das 09:00 às 13:00 hs. Em algumas ocasiões, a igreja é visitada simultaneamente por três grupos, num total de aproximadamente oitenta pessoas.

Além dos problemas de condensação, muitos turistas e visitantes tocam nas talhas barrocas, e se sentam nas tribunas de jacarandá da capela-mor, após cruzarem o cordão de isolamento sem nenhuma sanção por parte do guia de turismo. O uso do flash em monumentos históricos é proibido pelo IPHAN; em uma das observações participantes, o interior da igreja foi alvo de aproximadamente cento e cinqüenta flashes. Há poucos benefícios para a igreja dessas visitas; a responsável pela loja da igreja relatou que poucos turistas compram algum artigo religioso, ou doam dinheiro para a manutenção do monumento. A igreja é um típico exemplo de recurso comum (common pool resource) (Hardin, 1968), que, como coloca Briassoulis (2002), é explorado turisticamente ao máximo, sem que haja investimentos e cuidados necessários para se evitar sua deterioração e eventual extinção.

O padrão de exploração turística não dá muitas oportunidades para que o turista ou visitante gaste seu dinheiro em Igarassu. O fiteiro do Pátio dos Santos Cosme e Damião é praticamente o único negócio apto a receber esse gasto; a Foto 3 mostra esse pequeno comerciante local.

O trabalho de campo mostrou que os turistas e visitantes que visitam Igarassu através de agências gastam em média de $\mathrm{R} \$ 0,07$ a $\mathrm{R} \$ 0,27$. O exemplo de um grupo de vinte e sete turistas, que visitou o sítio histórico em 


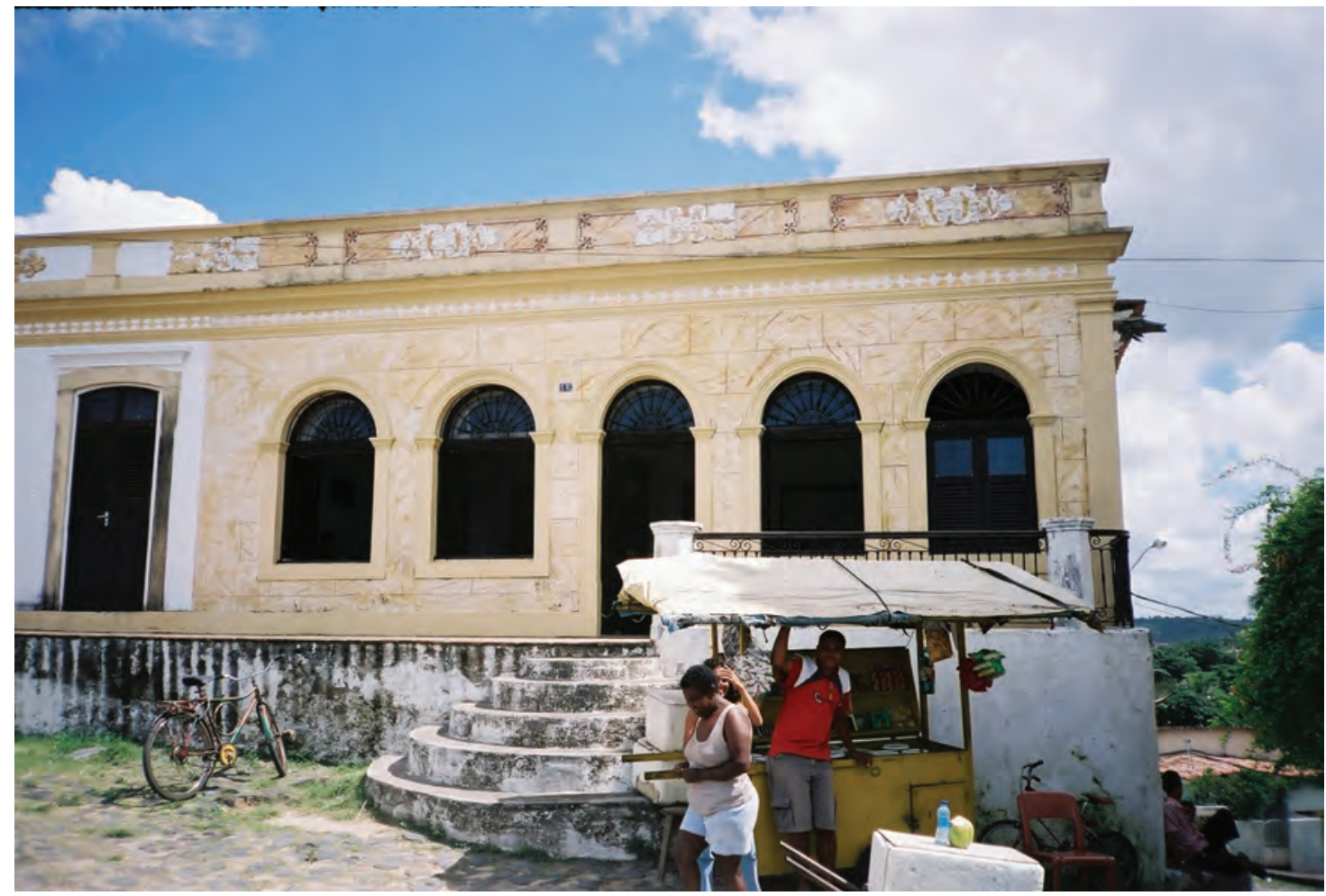

Foto 3: Fiteiro defronte ao MHI. Fonte: Autor. A foto é de junho de 2005.

julho de 2005, ilustra como se dá esse baixo gasto turístico. Os passageiros desceram do ônibus, e visitaram apenas a Igreja dos Santos Cosme e Damião, pois o guia de turismo não indicou o MHI, e cortou a visita à Igreja e Convento do Sagrado Coração de Jesus alegando falta de tempo. Nenhum turista fez compras na loja da igreja, e aparentemente também não deixou doações. Ao sair da igreja, três turistas compraram guloseimas e um turista comprou um coco-da-baía no fiteiro, gastando os quatro apenas $\mathrm{R} \$ 4,00$ no total. Dividindo-se esse gasto total pelo número de turistas, chega-se ao gasto médio do grupo: $\mathrm{R} \$ 0,07$ por passageiro.

Há dois serviços de guias existentes no sítio histórico: guias embaçadores e guias mirins. Os trinta guias mirins são adolescentes entre 14 e 18 anos incompletos, supostamente em situação de risco social - o trabalho de campo mostrou serem raros esses casos - que recebem uma bolsa mensal da PMIg para completar seus estudos. Eles trabalham no Pátio dos Santos Cosme e Damião em escalas de dez.

Os quinze guias embaçadores atuam também no Pátio dos Santos Cosme e Damião. O grupo funciona como uma cooperativa informal; o dinheiro coletado dos turistas é dividido igualmente entre todos que trabalharam no dia. Os guias entrevistados afirmam que trabalham no pátio para sobreviver; o trabalho de campo encontrou jovens de famílias pobres, atrasados na escola e às vezes arrimos de família. Temos aqui um exemplo do homem marginal (marginal man) de Smith (1989) - sujeito cujas características étnicas e/ou sociais situam-no à margem da sociedade -, facilmente encontrado nos destinos turísticos de países em desenvolvimento.

Não há disputas ou conflitos abertos entre os guias mirins e embaçadores, pois apenas os segundos abordam os turistas, visitantes e guias de turismo; os guias mirins permanecem sentados na calçada. Os guias mirins sentem medo dos guias embaçadores - mais velhos e ocasionalmente armados -, como ilustra o seguinte depoimento: "Nós não iremos disputar [turistas e visitantes] com eles, porque é capaz de a gente perder a vida." (Entrevista em Igarassu, 20/07/2005).

A remuneração mensal dos guias embaçadores varia de $R \$ 150,00$ a $R \$ 250,00$. Os guias de turismo delegam a narrativa sobre Igarassu para eles. Enquanto alguns guias de turismo conhecem os guias embaçadores pelo nome, e têm até certa intimidade, outros aceitam o serviço por medo de represálias; há vans e táxis cujos passageiros não chegam a desembarcar no pátio, provavelmente em virtude da abordagem agressiva dos guias embaçadores. Um guia de turismo diz: 
Não é possível fazer nada em Igarassu sem esses meninos, quando o ônibus pára, eles já estão na porta, falando sobre a cidade, e mandando os turistas irem a Cosme e Damião. [...] Daí, a gente leva [eles] para Itamaracá, pois é quando eles pedem dinheiro dos turistas, não tem opção. (Entrevista em Igarassu, janeiro de 2005).

A narrativa turística dos guias embaçadores centrase na descrição da Igreja dos Santos Cosme e Damião; são citadas datas, estilo arquitetônico e alguns casos anedóticos. A narrativa é pobre e fragmentada, até pela falta de escolaridade e treinamento - a maior parte dos guias embaçadores não sabe sequer falar sobre a história da própria cidade.

Outro problema é a ligação de guias embaçadores com o tráfico de drogas e prostituição que ocorrem nos arredores do sítio histórico. Muitos deles portam pequenas facas e canivetes, o que aumenta a sensação de insegurança e também de intimidação sobre os guias mirins. Já houve casos de assassinatos de guias embaçadores devido ao envolvimento em pequenos delitos ou tráfico de drogas.

É interessante observar como um pequeno número de jovens consegue imobilizar as ações da PMIg. No início de 2005, a prefeitura municipal tentou disciplinar o turismo no pátio através de policiamento da Guarda Municipal e instalação de posto de informações turísticas. O posto nunca saiu do papel. O policiamento foi implantado, mas os guias embaçadores protestaram, e ele foi suspenso. Eles relatam esse caso como uma vitória do grupo; os fatos foram confirmados por outros entrevistados:

Guia embaçador 1: No início do ano, a PMIg tentou tirar a gente daqui com a Guarda Municipal. Eles tiraram diversas vezes, mas a gente sempre voltava e acabamos ficando.

Guia embaçador 2: É aí que a gente tira o chapéu para ato do nosso prefeito Severino, o Ninho. Os guardas municipais estavam aqui, ele chegou, conversou conosco, disse que nunca tinha dado ordens para os guardas municipais atrapalharem nosso trabalho, liberou, e até hoje estamos trabalhando aqui. [...]

Guia embaçador 3: [...] A gente já falou para o prefeito Ninho: é melhor a gente ficar aqui em cima do que por aí, roubando, cheirando cola e chateando. (Entrevista em Igarassu, 20/07/2005).

\section{Considerações finais.}

O conjunto arquitetônico e paisagístico de Igarassu é um dos mais fiéis, íntegros e bem preservados legados materiais do Brasil Colônia (1500-1822), no qual o patrimônio arquitetônico e urbanístico combina-se a mangues, alagados e mata atlântica para criar um quadro de rara beleza. Entretanto, isso não tem bastado para atrair os vários elos do negócio turístico, nem para motivar a PMIg a adotar uma gestão pública de cultura e turismo mais conseqüente, que possibilitem um regime de visitação mais demorado e economicamente favorável.

$\mathrm{O}$ estudo de caso sobre Igarassu reflete as inter-relações entre patrimônio cultural, turismo e gestão pública em Pernambuco e no Brasil de forma geral, tendo suas particularidades. O trabalho de campo permite mostrar a posição secundária da cultura e turismo na estrutura do governo da PMIg e governo estadual - turismo é prioridade apenas no discurso. É notável a falta de um corpus de conhecimento sobre turismo, principalmente turismo cultural; é baixa a capacidade institucional desses órgãos.

Apesar de o turismo cultural começar a ocupar espaço no discurso de dirigentes públicos e mesmo de integrantes do trade turístico, o fomento e regulação da atividade são quase que reduzidos a como se garantir jornadas mais longas de abertura pública de monumentos, quando não discursos de boa vontade administrativa referentes à necessidade de se recuperar edificações degradadas. Alguns entrevistados mostraram falta completa de imaginação, não conseguindo pensar alternativas ao padrão de intervenção estatal vigente; poucos conseguiram discutir com um mínimo de profundidade o padrão de exploração turística atual.

O trabalho de campo também revelou que este padrão é - por incrível que pareça - um instrumento de desvalorização e deterioração do patrimônio cultural. $\mathrm{O}$ turismo gera reduzido rendimento financeiro aos monumentos explorados; trata-os como mero apêndice da oferta turística pernambucana, deteriora os bens culturais edificados, sem que os intermediários turísticos preocupem-se com isso, e passa a idéia ao turista de que qualquer "trocadinho" que seja basta como ingresso ou ajuda. A narrativa turística é pobre e fragmentada, obstaculizando a apreciação do patrimônio cultural. Os próprios turistas e visitantes entrevistados reclamam da brevidade da visita em Igarassu, insatisfeitos com a seleção feita pelos guias de turismo, centrada em bares, restaurantes e lojas de artesanato.

É difícil visualizar mudanças a curto e médio prazo no padrão de exploração turística do sítio histórico de Igarassu, e, conseqüentemente, nos seus impactos so- 
ciais, econômicos e culturais. O padrão de intervenção estatal da STCE é anacrônico, preocupando-se em promover projetos vistosos em detrimento de ações públicas efetivas de regulação, controle e promoção. O fluxo de turistas e visitantes é controlado por agências de turismo receptivo do Recife e João Pessoa, que, apesar do nome, funcionam na prática como firmas de transporte, deixando o guia de turismo estruturar seus passeios dentro de um típico comportamento rent seeking em busca de comissões.

Cabe, seguindo-se Tosun (2000), indicar que mudanças profundas nos padrões de exploração turística e intervenção estatal dependem da ação de atores externos à PMIg e trade turístico, como, por exemplo, agências multilaterais de cooperação, organizações não governamentais e universidades e centros de pesquisa. Infelizmente, cultura e turismo não ocupam lugar de destaque na agenda pública brasileira, nem são áreas prioritárias de intervenção do Terceiro Setor; logo, não há perspectivas animadoras de mudanças nas interrelações entre patrimônio cultural, turismo e gestão pública em Igarassu, pelo menos a curto e médio prazo.

Contudo, cabe apresentar quatro propostas básicas para a gestão pública de cultura e turismo em Igarassu. Primeiro, é preciso integrar o sítio histórico ao restante da cidade, possibilitando aos residentes locais conhecêlo e o apreciar. Ações de educação patrimonial, principalmente junto ao público escolar, e de utilização desse espaço para ensaios e apresentações culturais permitiriam que os residentes reconhecessem o sítio histórico como algo também seu. Segundo, é necessário buscar parcerias para a gestão e conservação do sítio histórico, a exemplo de o que fizeram cidades patrimoniais como, por exemplo, Santo André (Vila de Paranapiacaba) e Santana do Parnaíba. Não se trata de conseguir apenas recursos financeiros, mas principalmente novos conhecimentos, posturas e visões acerca da importância, tratamento e utilização do patrimônio cultural material.

Terceiro, cabe adotar uma postura ativa em relação ao desenvolvimento turístico do sítio histórico e cidade como um todo, e não apenas reagir - às vezes, nem mesmo isso - ao padrão de exploração turística atual. Cabe à PMIg tentar explorar o potencial turístico de Igaras$\mathrm{su}$ - patrimônio cultural material e imaterial, composto sol, mar e praia, reservas naturais etc. - formulando um produto turístico que permita um padrão de exploração turística mais demorado e rentável à cidade, e que também seja comunicado aos turistas que não se sujeitam à pauta das agências de turismo receptivo. Por fim, o conjunto arquitetônico de Igarassu talvez seja o mais bem preservado do Brasil atualmente - e mesmo o paisagístico encontra-se bem preservado em relação a outras cidades patrimoniais. Cabe à PMIg abandonar a crença de que o desenvolvimento turístico depende da formulação e implantação de grandes projetos "transformadores," e se preocupar com pontos que efetivamente atrapalham a visitação do sítio histórico, como, por exemplo, a falta de sinalização turística, de segurança e de manutenção urbana.

\section{Referências bibliográficas}

Ap, John e Wong, Kevin K. F.

2001 "Case study on tour guiding: professionalism, issues and problems". Tourism management, 22(5): 551-563.

Black, Annabel

1996 "Negotiating the tourist gaze: the example of Malta". Em Boissevain, Jeremy (Ed.), Coping with tourists: european reactions to mass tourism (pp. 112142). Providence: Berghahn Books.

Borg, Jan van der, Costa, Paolo, e Gotti, Giuseppe

1996 "Tourism in European heritage cities". Annals of tourism research, 23(2): 306-321.

Brasil

1976 Parecer da secretaria executiva do programa sobre o projeto de agenciamento da Praça Marechal Deodoro e restauração do mercado municipal, da casa $\mathrm{n}^{\circ} 83$ e fachadas do casario da Rua Joaquim Nabuco, em Igarassu, Estado de Pernambuco. Recife: Seplan/PR; FUNDARPE. Mimeografado.

Briassoulis, Helen

2002 "Sustainable tourism and the question of the commons". Annals of Tourism Research, 29(4): 10651085.

Bryon, Jeroen e Russo, Antonio Paolo

2003 "The tourist historic city". Annals of tourism Research, 30(2): 492-494.

Cooper, Chris, Fletcher, John, Wanhill, Stephen, Gilbert, David, e Shepherd, Rebecca

2001 Turismo, princípios e práticas. 2. ed. Porto Alegre: Bookman.

E.L.T. Consultoria, Igarassu, e Serviço de Apoio às Micro e Pequenas Empresas de Pernambuco

2002 Plano de gestão do turismo para o município de Igarassu: versão final. Recife: PMIg. Mimeografado.

Empresa de Turismo de Pernambuco

198-? Rota da memória histórica pernambucana - Igarassu. Recife: EMPETUR. Mimeografado.

Empresa de Turismo de Pernambuco

1997 Agenda 98 - plano de ações da EMPETUR: versão para análise e apreciações. Recife: EMPETUR. Mimeografado.

Freyre, Gilberto

1968a Guia prático, histórico e sentimental da cidade do Recife. 4. ed. Rio de Janeiro: Livraria José Olympio Editôra.

1968b Olinda: $2^{\circ}$ guia prático, histórico e sentimental 
de cidade brasileira. 4. ed. Rio de Janeiro: Livraria José Olympio Editôra.

Fundação do Patrimônio Histórico e Artístico de Pernambuco

1985 Restauração e instalação do museu do Convento de Santo Antonio. Recife: FUNDARPE. Mimeografado.

1993 Restauração do Convento Santo Antonio de Igarassú. Recife: FUNDARPE. Mimeografado.

Fundação Instituto Brasileiro de Geografia e Estatística 2003 Censo demográfico 2000: características gerais da população: resultados da amostra. Rio de Janeiro: IBGE.

2005 Produto interno bruto dos municípios: 1999-2002. Rio de Janeiro: IBGE.

Gazeta Mercantil

2000 Análise setorial: operadoras de turismo e agências de viagens. São Paulo: Gazeta Mercantil.

Hardin, Garrett

1968 "The tragedy of the commons". Science, 162(3859): 1243-1248.

Igarassu

199-? Dive into the history. Igarassu: PMIg.

Igarassu

2005 Inventário do potencial turístico de Igarassu. Igarassu: PMIg.

Instituto do Patrimônio Histórico e Artístico Nacional

1994 Bens móveis e imóveis inscritos nos livros do tombo do Instituto do Patrimônio Histórico e Artístico Nacional. Rio de Janeiro: IPHAN.

Jansen-Verbeke, Myriam

1998 "Tourismification of historical cities". Annals of Tourism Research, 25(3): 739-742.

Maitland, Robert

2006 "How can we manage the tourist-historic city? Tourism strategy in Cambridge, UK, 1978-2003". Tourism management, 27(6): 1.262-1.273.

McKercher, Bob

2002 "Towards a classification of cultural tourists". International journal of tourism research, 4(1): 29-38.

McKercher, Bob e Du Cros, Hilary

2002 Cultural tourism: the partnership between tourism and cultural heritage management. Binghamton: Haworth Hospitality Press.

McKercher, Bob e Du Cros, Hilary

2003 "Testing a cultural tourism typology". International journal of tourism research, 5(1): 45-58.

Meethan, Kevin

1996 "Consuming (in) the civilized city". Annals of tourism research, 23(2): 322-340.

Miceli, Sérgio

1984 "O processo de 'construção institucional' na área cultural federal (anos 70)”. Em Miceli, Sérgio (Org.), Estado e cultura no Brasil (pp. 53-83). São Paulo: Difel.

Nettekoven, Lothar

1979 "Mechanisms of intercultural interaction" Em De Kadt, Emanuel Jehuda (Org.), Tourism - passport to development?: perspectives on the social and cultural effects of tourism in developing countries (pp. 135-145). New York: Oxford University Press.

Reis Filho, Nestor Goulart

2006 Quadro da arquitetura no Brasil. 11. ed. São Paulo: Perspectiva.

Russo, Antonio Paolo

2002 "The 'vicious circle' of tourism development in heritage cities". Annals of tourism research, 29(1): 165182.

Smith, Valene L.

1989 "Introduction". Em Smith, Valene L. (Ed.), Hosts and guests: the anthropology of tourism (pp. 1-17). 2nd ed. Philadelphia: University of Pennsylvania Press.

Snaith, Tim e Haley, Art

1999 'Residents' opinions of tourism development in the historic city of York, England". Tourism management, 20(5): 595-603.

Taddei, Pedro

1998 "Os grandes projetos". Em Weffort, Francisco e Souza, Márcio (Orgs), Um olhar sobre a cultura brasileira (pp. 145-170). Rio de Janeiro: Associação de Amigos da FUNARTE.

Teixeira, José Monterroso

1998 Igarassu. Rio de Janeiro: Agir; Recife: Fundação Ricardo do Espírito Santo Silva.

Tirapeli, Percival

1999 As mais belas igrejas do Brasil. São Paulo: Metalivros.

Tosun, Cevat

2000 "Limits to community participation in the tourism development process in developing countries". Tourism management, 21(6): 613-633.

Tribe, John

1997 "The indiscipline of tourism". Annals of tourism research, 24(3): 638-657.

Universidade Federal de Pernambuco

1974 Igarassu: proposições urbanológicas. Recife: UFPE.

\section{NOTAS}

1. Essas informações foram recolhidas na FUNDARPE, pois o projeto foi aprovado no Sistema de Incentivo à Cultura do Estado de Pernambuco. Como a pasta do projeto reúne diversos documentos - muitos sem identificação e não datados -, optou-se por não se referenciar o conteúdo retirado da supracitada pasta.

Recibido:

$23 / 12 / 09$

Reenviado:

$15 / 10 / 10$

Aceptado:

$01 / 02 / 11$

Sometido a evaluación por pares anónimos 